\title{
Individual and contextual factors of happiness and life satisfaction in a low middle income country
}

DOI:

10.1007/s11482-017-9567-y

\section{Document Version}

Accepted author manuscript

Link to publication record in Manchester Research Explorer

\section{Citation for published version (APA):}

Sujarwoto, S., Tampubolon, G., \& Pierewan, A. (2017). Individual and contextual factors of happiness and life satisfaction in a low middle income country. Applied Research in Quality of Life. https://doi.org/10.1007/s11482017-9567-y

\section{Published in:}

Applied Research in Quality of Life

\section{Citing this paper}

Please note that where the full-text provided on Manchester Research Explorer is the Author Accepted Manuscript or Proof version this may differ from the final Published version. If citing, it is advised that you check and use the publisher's definitive version.

\section{General rights}

Copyright and moral rights for the publications made accessible in the Research Explorer are retained by the authors and/or other copyright owners and it is a condition of accessing publications that users recognise and abide by the legal requirements associated with these rights.

\section{Takedown policy}

If you believe that this document breaches copyright please refer to the University of Manchester's Takedown Procedures [http://man.ac.uk/04Y6Bo] or contact uml.scholarlycommunications@manchester.ac.uk providing relevant details, so we can investigate your claim.

\section{OPEN ACCESS}




\title{
Title Page
}

\section{Individual and contextual factors of happiness and life satisfaction}

\section{in a low middle income country}

\author{
Sujarwoto Sujarwoto \\ Universitas Brawijaya Malang Indonesia \\ sujarwoto@ub.ac.id \\ Gindo Tampubolon \\ University of Manchester \\ gindo.tampubolon@manchester.ac.uk \\ Adi Cilik Pierewan \\ Universitas Negeri Yogayakarta Indonesia \\ Adi.pierewan@uny.ac.id
}




\title{
Individual and contextual factors of happiness and life satisfaction
}

\section{in a low middle income country}

\begin{abstract}
Understanding individual and contextual factors of happiness and life satisfaction in a lowand middle-income country setting are important in the study of subjective well-being. This study aims to examine individual and contextual factors of happiness and life satisfaction in one of the happiest countries in the world: Indonesia. Data comes from the Indonesian Family Life Survey $2014(\mathrm{~N}$ individual $=31,403 ; \mathrm{N}$ household $=15,160 ; \mathrm{N}$ district $=297)$. Results from a three-level ordered logit model show that factors of happiness and life satisfaction are beyond individual factors. Happiness and life satisfaction are also strongly associated with factors within an individual's household and at the district government level. Individuals living in households with better economic welfare are happier and more satisfy. Poor health and unemployment have a detrimental effect on happiness and life satisfaction. Individuals living in districts whose governments' better deliver public services are happier and more satisfy. In contrast, those living in areas with conflict and violence is less happy and satisfy. Individual religiosity and community social capital in the form of indigenous tradition benefit individual happiness and life satisfaction.
\end{abstract}

Keywords: happiness, life satisfaction, three-level ordered logit model, Indonesia 


\section{Introduction}

Happiness and life satisfaction are ultimate goals of human life (Layard and Layard 2011). Both measures are used by an international development organisation as one of the indicators for measuring social progress (Durand 2015) and are considered as an important measure of quality of life in nations from Bhutan to France and the United Kingdom (Stiglitz, Sen, and Fitoussi 2008). Studies during the last decades have identified individual and contextual factors of happiness and happiness (Argyle 2003; Diener et al. 1999; Helliwell 2006). However, most of these studies have been focused on Western countries, particularly rich countries across Western Europe and North America; studies of individual and contextual factors of happiness are less well understood in low- and middle-income settings in nonWestern countries.

Study of individual and contextual factors of subjective well-being in a low- and middleincome country context may provide an understanding of the ways in which economic, political and social development and different cultural settings may affect individual happiness and life satisfaction. The limitations of economic indicators, particularly GDP, in accounting for individual wellbeing in low-income and developing countries are evident. As suggested by Graham, Higuera, and Lora (2009), growth is a necessary, but not sufficient, condition for poverty reduction. Other key factors - such as public investments in health, institutions that can ensure adherence to basic norms of equity and fairness, and collective investments in social insurance to protect citizens - are essential to sustain the gains that 
growth and development bring about and to increase the chances that a larger number of the world's poor can eventually have happy and fulfilling lives. Countries in Asia, Africa, and Latin America are undergoing market economy and social transformation. These countries are also the poorest and most under developed countries; many are facing formidable challenges such as civil wars and widespread poverty. Welfare state policies and social safety net programs in these countries are weak. As a result, access to different forms of social protection is limited, and that protection benefits a smaller part of the population (Ginneken 1999). Moreover, democracy and its institutions in such countries may not be as mature in those in Western countries (Cox, Falconer, and Stackhouse 2009; Rock 2009; Faúndez 2016). The widening democracy and political participation in most middle- and low-income countries may not guarantee better public policies that improve citizens' happiness and wellbeing (Welsch and Kühling 2016; Diaz- Serrano and Rodríguez- Pose 2012; Bjørnskov 2014; Bjørnskov, Dreher, and Fischer 2010). The condition of social capital in non-Western countries may differ from those in Western countries. Coleman and Coleman (1994) explains that social capital in non-Western countries may be relatively strong due to the presence of a communitarian culture ideology; in this context, rich social capital in those countries may be particularly beneficial for citizens' happiness, given that cohesive communities are more successful in promoting economic and social solidarity and therefore in enhancing citizens' wellbeing (Helliwell 2006; Uslaner 1999).

Indonesia provides an interesting case for the examination of individual and contextual factors of happiness and life satisfaction in a low-middle income and non-Western country settings. According to research, Indonesians are the world's most content people (Ipsos 
2011). Indonesia reported the highest levels of happiness, with 55\% of people claiming to be 'very happy'. This percentage is higher than those found in rich countries such as the UK and the US as well as those of other emerging markets country such as India, Mexico, and Brazil (which placed third, fourth and fifth, respectively, in the same study). The 2012 Happy Planet Index also found Indonesia to be among the happiest countries (ranking $14^{\text {th }}$ of 151 countries), with Indonesians experiencing more happiness than many richer nations such as Japan (ranking $\left.45^{\text {th }}\right)$, Germany (ranking $46^{\text {th }}$ ), France (ranking $50^{\text {th }}$ ), China $\left(\right.$ ranking $\left.60^{\text {th }}\right)$ and the US (ranking 105) (National Economic Foundation 2012). Indonesia's social development has also been progressing very well since the 1998 financial crisis in Asia. Indonesia's economic growth appears well positioned with a yearly average of 4-6\% since 2002 (World Bank 2008). The poverty headcount ratio, at $\$ 1.25$ (PPP), decreased sharply from $47.7 \%$ in 1999 to $16.2 \%$ in 2011 (World Bank 2012). The country's human development index increased dramatically from 0.479 in 1990 to 0.624 in 2011 (World Bank 2012).

Indonesia is also an emerging democratic country as its authoritarian political system was radically reformed in 1999. Citizens across the country now experience increased freedom to make their voices heard through the press, over which the government has continued to relax its control. According to Freedom House (2009), Indonesia was categorized as one of the liberal democratic countries in which citizens are able to enjoy free, fair and competitive elections as well as a large catalogue of civil liberties. According to the Gallup 2009 survey of the top five most religious countries in the world, Indonesia is ranked fourth; ninety-nine percent of Indonesians answered that religion plays an important role in their daily life. Results from the Indonesian Family Life Survey 2014 show that religiosity, as measured by 
whether daily prayer is carried out by respondents, is high with $96 \%$ of respondents reporting that they pray every day. Moreover, many regions of Indonesia are known for an indigenous tradition of community involvement (Grootaert 1999). In Indonesia, the generalised reciprocity aspect of social capital is best illustrated by the sociocultural ethic of gotong royong (meaning generalised reciprocity) both in rural and urban areas; this remains a strong social norm in Indonesia as well as a powerful determinant of social relationships within communities (Bowen 1986). These indigenous traditions, as well as current economic, social and political changes in the country, may affect individual subjective well-being.

This study aims to examine individual and contextual factors of individual happiness and life satisfaction in Indonesia. It combines insight from two strands of earlier research on individual and contextual determinants of well-being in developed countries (Argyle 2003; Blanchflower and Oswald 2008; Diener 2000; Graham, Higuera, and Lora 2009; Lane 2000). More specifically, our central focus is to investigate whether the variation of economic, politic and social development within sub-national governments or districts explain citizen happiness and life satisfaction. By doing so, we contribute to the literature on subjective wellbeing in several ways. Firstly, by focusing on a low-middle income country, we provide a contrast to the far more extensive work on subjective well-being that draws on data from wealthy countries (especially the UK, US and Western Europe). Secondly, prior studies have focused on happiness in Indonesia using small sample data (Jaafar et al. 2012). In this study, this research focuses not only happiness but also life satisfaction. We use rich and most recent population survey data of Indonesia Family Survey (IFLS) 2014 which covers 83\% Indonesia's population. The survey for the first time consists of life satisfaction data. It also 
has detailed information about individual characteristics associated with subjective wellbeing such as age, gender, education and employment status, religiosity, social capital, health and early childhood health, and personality. Thirdly, The three-level ordered logit model used in this study is able to account for the clustering of individuals within households and districts by separating their variance in happiness and life satisfaction from the household and district variance (Rabe-Hesketh and Skrondal 2008). Using this model is thus most appropriate for examining the effects of individual and contextual factors of well-being on individual happiness and life satisfaction. The next section presents a synthesis of the literature on individual and contextual factors of happiness, life satisfaction, and their theoretical interrelationship.

\section{Individual happiness and life satisfaction: Two strands of prior studies}

Subjective well-being consists of both the individual's emotional state and satisfaction with

life in general and specific domains (Diener 2000). Moods and emotions (termed positive and negative effect) reflect subjective well-being in the short term, while life and domain satisfaction result from a longer term evaluation of well-being. Happiness - or its more cognitive counterpart, life satisfaction, or subjective well-being - can be regarded as a paramount striving throughout human life.

Social scientists have long been interested in the study of how and why people are happy and unhappy or satisfy and unsatisfied with their life; they do so by identifying factors associated with happiness and life satisfaction. The findings of previous studies suggest that the factors 
contributing to individual happiness and life satisfaction fall into two broad categories: individual and contextual. Individual factors of happiness and life satisfaction pertain to the socio-demographic characteristics of individuals and their unique economic circumstances. The individual factors include gender, age, marital status, health and early childhood health, employment status, education, income, social capital, religiosity, personality, and leisure (Argyle 2003; Diener 2000; Diener and Biswas-Diener 2011; Graham and Felton 2006; Bjørnskov, Dreher, and Fischer 2010). Contextual factors of happiness and life satisfaction pertain to factors at the community and state level such as social capital, democracy, better environment, good government and per capita GDP (Bjørnskov, Dreher, and Fischer 2010; Bjørnskov 2008; Argyle 2003; Lim and Putnam 2010; Veenhoven 2000; Helliwell et al. 2014; Rodríguez-Pose and Maslauskaite 2012).

Individual factors of happiness and life satisfaction have been identified by most psychologists and economists. Studies have found gender (Graham 2012), age (Argyle 2003), marital status (Argyle and Furnham 1983), health and early childhood health (Graham, Higuera, and Lora 2009), employment status (Clark and Oswald 1994), education (Gerdtham and Johannesson 2001), income (Lane 2000), social capital (Miller et al. 2006), religiosity (Abdel-Khalek 2006), loneliness (Lane 2000), personality (DeYoung et al. 2010; Soldz and Vaillant 1999; Costa Jr et al. 1986), and leisure to be predictors of individual happiness and life satisfaction (Argyle 2003).

Women tend to be happier than men (Graham 2012); one somewhat contentious explanation for this is that women tend to have lower levels of aspiration and, thus, a higher level of 
happiness and life satisfaction (Frey and Stutzer 2010). Age is positively associated with happiness and life satisfaction, with older people likely to be happier and more satisfy than younger people (Argyle 2001). Blanchflower and Oswald (2008) posited a U-shaped relationship between age and subjective well-being, demonstrating that both younger and older people tend to be happier and more satisfy with their life than middle-aged people. Marital status is a consistent predictor of happiness and life satisfaction (Argyle and Furnham 1983). Argyle and Furnham (1983) explain that marriage is the greatest sources of social support for most people, more than friends or kin, including emotional and material support and companionship.

Mixed finding on the relationship between education status, happiness, and life satisfaction. Graham (2012) explains education may contribute to happiness and life satisfaction by enabling individuals to better adapt to changing environments. However, education also tends to raise aspiration levels which may, if unmet, decrease happiness and life satisfaction. However, household and individual income are consistent predictors of happiness (Lane 2000). Physical health is a stable predictor of well-being; a healthy individual is likely to be happier and more satisfy with their life than an unhealthy individual (Graham, Higuera, and Lora 2009). Employment is positively associated with happiness and life satisfaction, with employed people likely to be happier and more satisfy with their life than those who are unemployed (Clark and Oswald 1994). In contrast, unemployed status has detrimental effect on individual happiness and life satisfaction (Clark and Oswald 1994). Loneliness harms for well-being (Lane 2000). 
Psychological literature also documented the association between individual personality and well-being (Soldz and Vaillant 1999; DeYoung et al. 2010; Judge, Heller, and Mount 2002; DeYoung, Peterson, and Higgins 2002; Costa Jr et al. 1986). Costa Jr et al. (1986) found that individual with high in extroversion tend to experience more positive emotions and also engage in more behaviours that produce happiness. In contrast, an individual with neuroticism tends to experience more negative emotions like depression and emotional instability. Religiosity and social capital are also factors of individual happiness. AbdelKhalek (2006) found that people who are religiously devout tend to enjoy not only better mental health but also higher levels of happiness. Studies in developed countries seem to largely confirm to largely confirm the benefits of social capital on well-being (Lim and Putnam 2010). Happiness and life satisfaction are also associated with leisure activities such as browsing the Internet (Argyle 2003; Stepanikova, Nie, and He 2010).

Contextual factors of happiness and life satisfaction have been a consistent topic of interest for sociologists, economists, and political scientists. Research shows community social capital (Lim and Putnam 2010), democracy (Frey and Stutzer 2000), good government and GDP (Bjørnskov, Dreher, and Fischer 2010; Di Tella, MacCulloch, and Oswald 2003) to be good predictors of happiness and life satisfaction.

In particular, earlier studies have shown the benefit of community social capital for individual happiness and life satisfaction (Putnam, Leonardi, and Nanetti 1994; Lim and Putnam 2010; Bjørnskov 2008). Lim and Putnam (2010) explained that social capital provides a channel for the personal and social support that increases individual happiness. Frey and Stutzer (2010) found that local autonomy and direct democracy both increase happiness, and they 
suggested that this positive effect could be attributed to two factors: local citizens' feeling of being more closely connected to political outcomes, and the benefits of political participation. However, Veenhoven (2000) found that political and private freedoms exert a positive influence on subjective wellbeing only in countries with well-established democracies. Rodríguez-Pose and Maslauskaite (2012) found that good government as measured by its capacity to deliver public services is positively associated with citizen happiness. Bjørnskov (2014) found that the higher performance of economic and judicial institutions affects happiness in medium- and high-income countries. Some scholars have also found that higher GDP increases citizen happiness. Corruption has a detrimental effect on happiness (Bjørnskov, Dreher, and Fischer 2010). Di Tella, MacCulloch, and Oswald (2003) and Helliwell et al. (2014), among others, have shown that people who live in countries with higher GDPs have higher levels of happiness and life satisfaction.

Whereas some of these factors have been tested and supported in the context of high-income countries as well as across countries, this study differs in that it examines the same factors in the context of a low-middle income country. This study aims to understand whether and to what extent these individual and contextual factors are also associated with happiness and life satisfaction of Indonesian citizens. The next section describes our data and statistical analysis in detail.

\section{Indonesian Family Life Survey and official statistics}

To examine individual and contextual factor of individual happiness and life satisfaction in Indonesia, we assembled individual and district level data from various sources. In this analysis, the data possesses a multilevel structure, with individuals nested within households 
and districts. Data on individuals and households is taken from IFLS 2014, while district data comes from Indonesian Village Potential Census (PODES), Indonesian Population Census, and official statistics.

IFLS is a continuing longitudinal socioeconomic and health survey in Indonesia. The survey was based on a sample of households representing $80 \%$ of the entire Indonesia population living in 13 provinces of the nation's 26 provinces in 1993. The survey collects data on individual respondents, their families, their households, and the communities in which they live. Overall, the survey has successfully re-interview over $86.5-91.5 \%$ of households in the original sample (Thomas et al. 2012). This low attrition is exceptional compared with surveys in other countries, including a longitudinal household economic survey in the United States (Thomas et al. 2012). In this analysis, we use IFLS 2014 which for the first time asking individual life satisfaction. The sample was restricted to respondents aged 14 years and older, for whom there was complete on happiness and life satisfaction. The sample included 36,385 individuals from 15,160 households living in 297 districts, which corresponds to approximately $86 \%$ of the IFLS 2014 sample included in the happiness and life satisfaction module. On average, there were 2.4 individuals within each household and 51 households within each district and 123 individuals within each district.

The IFLS data was linked to a number of other surveys and official statistical datasets using district codes. First, we linked it with the government Village Potential Statistics (PODES) census 2014. PODES contains detailed information about the incidence of local conflict and violence as well as the number of community groups within districts, calculating aggregates 
at the village and urban neighbourhood levels to measure their distribution. Next, we linked the IFLS data with the Indonesia Democracy Index data 2014 which retrieved from IDI project website (http://www.idiproject.org/). Third, we linked the IFLS data to district fiscal data. Collected by the Ministry of Finance, this dataset provides information about district spending for public services (Indonesian Ministry of Finance 2008). We use fiscal data from 2013 (the year prior to the IFLS survey), as district development spending in the Indonesian budgeting system takes at least one year to take effect.

\section{Measure of individual happiness and life satisfaction}

In the survey, happiness is measured by a question "Taken all things together how would you say things are these days-would you say were very happy, happy, unhappy or very unhappy" Meanwhile, life satisfaction is measured by a question "Please think about your life as a whole. How satisfied are you with it? Completely satisfied, very satisfied, somewhat satisfied, not very satisfied, and not all satisfied". Both questions have been widely used and been validated during use by previous studies (Frey and Stutzer 2010; Krueger and Schkade 2008; Oswald and Wu 2011). Studies summarize a number of ways to validate happiness and life satisfaction data, and demonstrate that self-rated happiness and life satisfaction is strongly correlated with objective wellbeing (Frey and Stutzer 2010; Krueger and Schkade 2008; Oswald and $\mathrm{Wu} 2011$ ). Stable happiness and life satisfaction numbers are found over time (Krueger and Schkade 2008), and a strong match has been found between subjective and objective wellbeing (across the United States, by (Oswald and Wu 2011)). The majority of respondents fell into one of the 'happy and very happy' (91.4\%) and 'somewhat satisfy and 
very satisfy' $(81.7 \%)$ categories. Summary statistics of sources of happiness and life satisfaction are presented in Table 1.

Table 1. Summary statistics of sources of happiness and life satisfaction in Indonesia

\section{Individual, household and district factors of happiness and life satisfaction}

\section{Individual factors of happiness and life satisfaction}

Age is measured by a continuous variable of respondent's age. The average age of respondents is 38 years old. Gender and marital status are measured by a dummy variable describing a female ( $1=$ female, $0=$ male $)$ and a married individual $(1=$ married, $0=$ single, divorce and widow). The data shows half the respondents were a female and $71 \%$ of them married. To examine the relationship between these variables, we construct the number of years a respondent attended school as a measure of education. We found most respondents are educated in secondary high school representing 9 years in Indonesia's education system. A dummy variable of employment status was constructed to address the issue of whether being unemployed has a detrimental effect on happiness and life satisfaction. The proportion of unemployed in the IFLS 2014 is $7 \%$.

Health is measured by self-reported health and early childhood health. The IFLS 2014 survey asks, 'In general, would you say that you are 'very healthy', 'sufficiently healthy', 'less than healthy', or 'unhealthy'?" We combine the first two categories as 'good health', and the last two as 'poor health', and find that $21 \%$ of respondents report having poor health. Prior studies 
documented a strong effect of childhood health on adult mental health and well-being (Kessler et al. 2010; Case, Fertig, and Paxson 2005). The survey asked early childhood health with a question "Would you say that your health during your childhood was in general excellent, very good, good, fair, or poor?" The first two categories are combined to be good health, while the last two categories are combined to be poor health. The survey also asked respondents whether they have experienced emotional, nervours, or psychiatric problem during childhood with a question "Did you have any of emotional, nervous, or psychiatric problem during your childhood (that is, from when you were born up to and including age 15)?" we found $37 \%$ individuals reported having poor health and $7 \%$ having emotional, nervous, or psychiatric problem when they was child.

Personality is measured by big " 15 items measures of big five personalities" and we used the questions to measure whether openness, conscientiousness, extroversion, agreeableness, neuroticism personality of adult affect their well-being. We found most of individuals answer agree on a little that they are someone having agreeableness, openness, and conscientiousness personality. In this study, we used community participation to measure individual social capital (Sujarwoto and Tampubolon 2013). Individual participation was calculated by the percentage of community activities known to the respondent in which they also participated within the past year out of a list of 12 . The other personal variables that strongly affects happiness is loneliness and religiosity. Lane (2000) finds that loneliness has a depressing effect on happiness, and to control for this we construct a dummy variable indicating whether respondents' spouse lives away from home ( $1=$ spouse live away from home, $0=$ live in the same home). We find 5\% of respondents report in the affirmative. To determine whether 
religiosity matters to happiness and life satisfaction, we thus construct a variable to indicate whether respondents carry out a daily prayer; the majority of respondents report that they do. Leisure activities are measured by whether respondents use their mobile phone for entertainment/multimedia or Internet browsing. We found $42 \%$ respondents use their mobile phone for these activities.

\section{Household factors of happiness and life satisfaction}

We use household expenditure as a proxy for income to measure poverty, as information regarding the latter is often biased and difficult to assess in developing countries, particularly in subsistence farming households (Deaton and Zaidi 2002; Jorgenson 2002). This study refers to household expenditure adjusted with the 2014 consumer price index data for urban and rural areas. The average real monthly household expenditure in 2014 was IDR1, 875,000 (USD187.5).

\section{District factors of happiness and life satisfaction}

District-level variables include GDP, community social capital, democracy, spending for public services, and local conflicts and violence. GDP is used to capture economic development. The density of social groups is used to measure community social capital. Following Putnam et al. (1993), we use the density of social groups active in a district to measure community social capital. This provides information about, among others, kelompok pengajian and kelompok kebaktian (religious groups), karang taruna (youth groups), persatuan kematian (funeral groups), and kelompok wanita (women's groups), all active community groups found within villages or urban neighbourhoods. We calculated the 
aggregate number for each active social group within a district and found that community social capital varies across districts.

District democracy is measured by district democracy index from IDI project (The Ministru of Home Affairs 2014). The mean democracy index in Indonesia 2014 is 72.82 . We use district spending for public services to measure district capacity to deliver public services (Bjørnskov 2008). To address whether local conflicts and violence affect happiness, we include the number of local conflicts and violence in the estimation; local conflicts and violence indicate an inability on the part of local democracy to guarantee effective local leadership as well as a weak capacity of district authorities to manage both their responsibilities and resources.

\section{The three-level ordered logit regression}

A three-level ordered logit regression is used to account for individual, household and district characteristics on happiness and life satisfaction. This model is more appropriate than the use of single ordered logit regression, which aggregates data at the individual level and ignores the nested structure of data; if ignored, this nesting of individuals within household and district units can lead to the underestimation of standard errors regarding the effect of household and district characteristics (Snijders and Bosker 1999). One consequence of failing to recognise hierarchical structures is that standard errors of the regression coefficient will be underestimated, leading to an overstatement of statistical significance. Standard errors of the coefficient of higher-level predictors will be the most affected by ignoring the grouping as does single ordered logit estimation. 
Three-level ordered logit model, or multilevel, analyses combine the regression and the variance component models to account for the nested structure of the data. This model accounts for the clustering of individuals by separating individual variance in happiness from that of household and district variance in happiness and life satisfaction. The total variance is partitioned into the variance between households and districts $\left(\sigma_{\mu}^{2}\right)$ and the variance within households and districts $\left(\sigma_{e}^{2}\right)$. These variances capture the effects of unobserved heterogeneities, variables that are independent of the covariates in the model (Rabe-Hesketh et al. 2012). We carried out three-level ordered logit models with Generalised Linear Latent and Mixed Models commands (GLLAMMs) using Stata 14.0 software. Rabe-Hesketh et al. (2004) explained that GLLAMMs are a class of multilevel latent variable models for (multivariate) responses of mixed type, including continuous responses, counts, duration/survival data, dichotomous, ordered and unordered categorical responses, and rankings. In this analysis, GLLAMM is used with an ordinal logit link as the dependent variable (self-rated happiness and life satisfaction) is ordinal. For each of the models, the estimated coefficient, standard errors, individual, household and district variances, and log likelihood as an indicator of model fit are reported. All models were estimated using maximum likelihood estimation. Lastly, we applied the ordered logit model to extract marginal effects of each factor on observed probabilities of happiness and life satisfaction. The marginal effects provide evidence of the magnitude of association of individual and contextual factors of happiness and life satisfaction.

\section{Results}


We begin by presenting the distribution of happiness and life satisfaction and bivariate analysis. Then, we present results of three level ordered logit regression.

District distribution of happiness and life satisfaction and bivariate analysis

The mean of self-rated happiness and life satisfaction score was $3.00(\mathrm{SD}=0.50)$ and 3.32 $(\mathrm{SD}=0.80)$. Most respondents in the surveys report happy/very happy $(91.4 \%)$ and satisfy/very satisfy $(81.7 \%)$. Figure 1 describes the distribution of happiness and life satisfaction across districts in the IFLS 2014 sample. Variation of happiness and life satisfaction across districts are shown in the data.

Bivariate ordered logit regression analysis shows that most variables were statistically significantly associated with happiness and life satisfaction at the 5\% level. In the individual and household level, it shows most of variables are significantly associated with happiness and life satisfaction. Age, being female, being married and being healthy correlated positively with both subjective well-being measures, whereas loneliness and being unemployed exhibited an inverse relationship with happiness and life satisfaction. In the district level, district community social capital and spending for public services are strongly related to happiness and life satisfaction. GDP has a positive association with both indicators. Local conflict and violence are negatively associated with citizen happiness and life satisfaction. Democracy index failed to achieve statistical significance. 
Only a small number of observations were missing. With the relatively small amount of missing data, it is expected that bias and efficiency loss in the estimation of the multivariate models were minimal.

\section{Three level ordered logit analysis}

Table 2 shows results of the three-level ordered logit model. To examine the degree of variance in individual happiness at the individual, household, and district levels, we estimated an empty model before regressing happiness and life satisfaction on any predictors. The empty model includes only variance components; it is not reported in the tables. It revealed that the unexplained individual variance in happiness and life satisfaction is 0.049 and 0.045 respectively, the unexplained household variance in happiness and life satisfaction is 0.038 and 0.032 respectively, and the unexplained district variance comes to 0.007 and 0.006 respectively. Intra-class correlation (ICC) for individuals within a district the ICC is 0.180.20. This means that $18-20 \%$ of the variation occurs between districts; ignoring this can lead to inefficient and biased estimates.

[Table 2. Results of three level ordered logistic regression and marginal effects of happiness and life satisfaction]

We begin by explaining variables at individual and household level. Age has U-shaped relationship with happiness and life satisfaction with younger individual likely less happy 
and satisfy, while older people likely happier and more satisfy with their life. The association of age on both indicators of subjective wellbeing is quite small (4\% and $3 \%$ respectively). Female is happier and more satisfy with their life than male. However, the association is not statistically significant for happiness. The association of female on life satisfaction is $12 \%$, meaning the probability of female being satisfied with their life was $12 \%$ higher than male.

As expected, being married benefits for individual well-being. The association of married on happiness was larger than its association on life satisfaction (9\% and 5\% respectively). Education also benefits for well-being but the association of education on both indicators of subjective well-being is very small (0-1\%). An unemployed individual has lower well-being than an employed individual. The probability of an unemployed individual being less happy and less satisfied was $8 \%$ and $12 \%$ than individual who employed.

Poor health and poor childhood health also harms for well-being. The magnitude association of having an emotional, nervous or psychiatric problem during childhood on adult happiness was quite large (32\%). Likewise, a lonely individual is less happy and satisfy with their life. The probability of happiness and life satisfaction among individuals who living separated with their spouse was 8-9\% lower than those who living together. Religiosity and community participation provides social support which good for well-being. Across the models, we found a positive association between both variables and well-being. We found the probability of a religious individual being satisfied with their life was $19 \%$ larger than a non-religious individual. Leisure activities such as using mobile phone for entertainment is good for happiness and life satisfaction. However, the association of mobile phone use on happiness and life satisfaction was small. A contrast relationship is shown on the association between 
personality and well-being. Conscientiousness, extroversion, and agreeableness individuals are likely happier and more satisfied that neuroticism individuals. Household expenditure is significantly positively associated with happiness and life satisfaction. The association of household expenditure on life satisfaction was larger than its association on happiness (6\% and $3 \%$ respectively).

At district level, it shows that districts with better economic development as indicated by higher GDP have higher well-being. However, the association of local government GDP on well-being was small (1-2\%). Community social capital and spending for public services which capture district capacity in providing social support and services for communities also positively associated with happiness and life satisfaction. The association of community social capital on both well-being measures was quite large (13\% and $31 \%$ respectively). In contrast, local conflict and violence have a detrimental effect on citizen well-being. We found individuals who live in conflict districts was less happy and satisfied with their life than those live in non-conflict districts. Democracy index is not significantly associated with both subjective well-being measures.

The variances at the household and district levels are significant across all specifications. The estimation of these works towards ensuring that remaining estimates are robust against unobserved household and district heterogeneities. Single-level studies, which ignore unobserved heterogeneities at either the household or the district level may not be as robust. This is worth bearing in mind when comparing these results with those discussed in the current literature. 


\section{Discussion and conclusion}

In this paper, we explore individual and contextual factors of happiness and life satisfaction in the context of low middle-income country. Indonesia provides an interesting case not only because recent findings show the country to be one of the happiest in the world but also because relatively little research has explored the factors of individual happiness and life satisfaction in the country. The main results suggest that happiness and life satisfaction among Indonesians is significantly and positively associated not only with personal factors but also with household and district government capacity factors.

Confirming studies in the context of developed countries, the results show happiness and life satisfaction are likely to increase with age as older individuals have lower aspiration than younger individuals, and more than this the goal-achievement gap is smaller (Argyle 2003). In all models show that females tend to be more satisfied with their life than males. This may indicate the differences between what affects male and female's levels of life satisfaction in the country. Echoing Graham (2012), in Indonesia, most female tend to focus on personal and domestic problems, while men concern themselves more with matters outside of the home. Likewise, females tend to be happier than males but the gaps were no significance differences.

Marriage becomes an important predictor of well-being since it provides economic, emotional and social support form one spouse and children (Diener 2000). Conversely, being lonely is likely to decrease happiness (Lane 2000). The association of marital status on 
wellbeing was larger than other individual factors which may indicate the importance roles of marital status on wellbeing in Indonesia's culture. Pisani (2014), for example, explains that in Indonesia's traditional culture, marriage is viewed as the way to get full adults status. It is also viewed as one important means of advancing individual or family social status. In this traditional culture, individuals who are married and individuals who are not married differ in all sorts of other ways such as getting stereotyped, excluded or discriminated against and these may account in the happiness of non-married individual (Pisani 2014).

Education is strongly related to income and occupation status and therefore holding a higher level of education makes individual happier and more satisfied with their life (Graham 2012). The small association between education and wellbeing may indicate the low impact of education on individual's ability to earn in Indonesia. As the findings show most of respondents were educated at primary school. Likewise, household expenditure as a proxy measure of family economic welfare relates to happiness and life satisfaction. However, the association between family economic welfare and happiness was small which may confirm that family economic welfare has only mattered very little on individual happiness in Indonesia.

Being unhealthy makes people less happy and less satisfy with their life (Oswald and Wu 2011). Since early childhood determines adult health, early childhood health, therefore matters for adult well-being (Luo and Waite 2005). The long arm of the detrimental effect of poor childhood health on adult well-being in the county was shown from a large magnitude association of having a psychiatric problem in early childhood on happiness. As might be 
expected, unemployment hurts well-being (Argyle 2003). This study confirms that those who are unemployed are less happy and less satisfy than those who are employed.

Since Indonesia has a rich indigenous tradition of social groups, many people have a good chance of joining such groups. Results suggest that participation in community groups is better for individuals' well-being. Helliwell (2006) explains that such individual community participation may facilitate social networks and support mechanism which positively affect well-being. Moreover, the importance role of community social capital as sources of individual happiness and life satisfaction in Indonesia was shown from its large association. Across the models, we found the association of community social capital on wellbeing was larger than the association of individual participation in community activities on wellbeing.

Indonesia is one of most religious countries (Gallup 2009) which means religion and activities related to religion plays an important role in individual and community daily life. We found that all of these religious activities benefit for individual wellbeing. Across the models, it shows that religious individuals are happier and satisfied with their life than nonreligious individuals. This finding confirms prior cross countries study that shows a positive association between religiosity and subjective wellbeing (Argyle 2003).

The recent IFLS 2014 survey for the first time asked "big five personality indicators" (Smith 2013). In this study, we used these indicators to identify the association between each type of personality and wellbeing. Confirming earlier studies, we found positive association between conscientiousness, extroversion, agreeableness, and happiness, whereas a negative association between neuroticism and well-being. Costa Jr et al. (1986) found that an 
individual with high in extroversion tends to experience more positive emotions and also engage in more behaviours that produce happiness. In contrast, an individual with neuroticism tends to experience more negative emotions like depression and emotional instability. However, the association of each type of personality on wellbeing was small, indicating the wellbeing differences among them are relatively low.

The findings also show a positive association between district economic development and subjective well-being These findings confirm Clark and Senik (2011) and Di Tella, MacCulloch, and Oswald (2003) who also documented the positive effect of GDP on subjective well-being using cross countries data. Better district competence, as indicated by the capacity to deliver public services, is significantly associated with well-being; democracy as measured by democracy index is not. These contrasting results seem to signal that happiness in this emerging democracy is increased through better capacity of district government to deliver public services rather than through the democratic opportunities offered by direct political participation (Sujarwoto and Tampubolon 2015). The emerging district direct local democracy in Indonesia has been accompanied by an increasing amount of local conflict, which has not only rendered local democracy less effective (Van Klinken 2007) but has also in itself had a detrimental effect on happiness and life satisfaction of its people. This study demonstrates that both local conflicts and violence have a detrimental effect on citizen happiness and life satisfaction. Further, the small association of district GDP and district spending on public services on individual wellbeing also signal the lack capacity of most district government in the country in managing economic and financial resources following decentralisation reform (Sujarwoto and Tampubolon 2015). 
This study has a number of limitations which need to be addressed. Firstly, because of its cross-sectional design, we must be cautious about the possible causality of associations. The estimated coefficient should be viewed as a measure of association rather than of causation. Almost every variable in our model could be considered endogenous, as happiness affects almost all aspects of social, political, and economic life for both individuals and institutions (Graham, Higuera, and Lora 2009). Secondly, self-rated happiness and life satisfaction (which this study uses) is only one measure of subjective wellbeing; Diener (1984) identifies a number of others - level of life satisfaction, positive affect (i.e. satisfaction with the past and current life) and negative affect (i.e. anxiety and depression) - and future study may also examine the effect of decentralisation on these measures. In addition, the single-item selfreport scales used in this study may also limit the sophistication of the interpretation of results and the reliability of the measures used. Stock et al. (1982), for example, explain that singleitem scales tend to be less reliable over time than multi-item scales (although we note that the temporal reliability of single-item measures has been moderately high).

Despite these limitations, we have been able to demonstrate a number of implications that are valid for the well-being literature as well as for policy makers. Firstly, this study shows happiness and life satisfaction are not only associated with personal issues but also is strongly associated with contextual issues. The results show that the degree of individual happiness and life satisfaction varies across households and districts, and that it is significantly associated with household socio-economic characteristics as well as local politics and local socio-economic conditions. From an empirical perspective, this study, therefore, suggests that it is essential to consider a range of district social, economic, and political variables and 
to examine their effects on wellbeing. By substantially enlarging the scope of potential questions put to respondents, multilevel analysis provides the most appropriate basis for developing a detailed contextual description of how such contextual factors affect individual well-being.

Second, in the context of a newly democratic, a low middle-income country, better economic development and the quality of district administration seems to be more important for citizen wellbeing than the provision of local democracy and the freedoms it implies. As we have already noted, citizens' report being happier when their district authorities prove themselves more capable of delivering local economic development and in providing better public services and promoting community social capital. Echoing Clark and Senik (2011) thus providing better policies and services that can ensure adherence to basic norms of equity and fairness, as well as promoting social support and collective culture, are essential to increasing citizen happiness and life satisfaction in a low middle-income country settings. The importance of the role of districts in improving well-being in the context of a low middleincome country is clearly paramount and should not be underestimated.

\section{References}

Abdel-Khalek, Ahmed M. 2006. 'Happiness, health, and religiosity: Significant relations', Mental Health, Religion \& Culture, 9: 85-97.

Argyle, Michael. 2003. '18 Causes and Correlates of Happiness', Well-being: The foundations of hedonic psychology, 353.

Argyle, Michael, and Adrian Furnham. 1983. 'Sources of satisfaction and conflict in longterm relationships', Journal of Marriage and the Family: 481-93.

Bjørnskov, Christian. 2008. 'Social capital and happiness in the United States', Applied Research in Quality of Life, 3: 43-62. 
- 2014. 'Do economic reforms alleviate subjective well-being losses of economic crises?', Journal of Happiness Studies, 15: 163-82.

Bjørnskov, Christian, Axel Dreher, and Justina AV Fischer. 2010. 'Formal institutions and subjective well-being: Revisiting the cross-country evidence', European Journal of Political Economy, 26: 419-30.

Blanchflower, David G, and Andrew J Oswald. 2008. 'Is well-being U-shaped over the life cycle?', Social Science \& Medicine, 66: 1733-49.

Bowen, John R. 1986. 'On the political construction of tradition: Gotong royong in Indonesia', The Journal of Asian Studies, 45: 545-61.

Case, Anne, Angela Fertig, and Christina Paxson. 2005. 'The lasting impact of childhood health and circumstance', Journal of health economics, 24: 365-89.

Clark, Andrew E, and Andrew J Oswald. 1994. 'Unhappiness and unemployment', The Economic Journal, 104: 648-59.

Clark, Andrew, and Claudia Senik. 2011. 'Will GDP growth increase happiness in developing countries?'.

Coleman, James S, and James Samuel Coleman. 1994. Foundations of social theory (Harvard university press).

Costa Jr, Paul T, Catherine M Busch, Alan B Zonderman, and Robert R McCrae. 1986. 'Correlations of MMPI factor scales with measures of the five factor model of personality', Journal of Personality Assessment, 50: 640-50.

Cox, Dan G, John Falconer, and Brian Stackhouse. 2009. Terrorism, instability, and democracy in Asia and Africa (UPNE).

Deaton, Angus, and Salman Zaidi. 2002. Guidelines for constructing consumption aggregates for welfare analysis (World Bank Publications).

DeYoung, Colin G, Jacob B Hirsh, Matthew S Shane, Xenophon Papademetris, Nallakkandi Rajeevan, and Jeremy R Gray. 2010. 'Testing predictions from personality neuroscience brain structure and the big five', Psychological science.

DeYoung, Colin G, Jordan B Peterson, and Daniel M Higgins. 2002. 'Higher-order factors of the Big Five predict conformity: Are there neuroses of health?', Personality and Individual differences, 33: 533-52.

Di Tella, Rafael, Robert J MacCulloch, and Andrew J Oswald. 2003. "The macroeconomics of happiness', Review of Economics and Statistics, 85: 809-27.

Diaz- Serrano, Luis, and Andrés Rodríguez- Pose. 2012. 'Decentralization, Subjective Well- Being, and the Perception of Institutions', Kyklos, 65: 179-93.

Diener, Ed. 2000. 'Subjective well-being: The science of happiness and a proposal for a national index', American psychologist, 55: 34.

Diener, Ed, and Robert Biswas-Diener. 2011. Happiness: Unlocking the mysteries of psychological wealth (John Wiley \& Sons).

Diener, Ed, Eunkook M Suh, Richard E Lucas, and Heidi L Smith. 1999. 'Subjective wellbeing: Three decades of progress', Psychological bulletin, 125: 276-302.

Durand, Martine. 2015. 'The OECD Better Life Initiative: How's Life? and the Measurement of Well- Being', Review of Income and Wealth, 61: 4-17.

Faúndez, Julio. 2016. Good government and law: Legal and institutional reform in developing countries (Springer).

Freedom House. 2009. Freedom in the world 2009 (Freedom House: Washington DC). 
Frey, Bruno S, and Alois Stutzer. 2000. 'Happiness, economy and institutions', The Economic Journal, 110: 918-38.

- 2010. Happiness and economics: How the economy and institutions affect human well-being (Princeton University Press).

Gerdtham, Ulf-G, and Magnus Johannesson. 2001. 'The relationship between happiness, health, and socio-economic factors: results based on Swedish microdata', The Journal of Socio-Economics, 30: 553-57.

Ginneken, V. 1999. 'Overcoming social exclusion.' in V. Ginneken (ed.), Social Security for the Excluded Majority: Case studies of Developing Countries (ILO: Geneva).

Graham, Carol. 2012. Happiness around the world: The paradox of happy peasants and miserable millionaires (Oxford University Press).

Graham, Carol, and Andrew Felton. 2006. 'Inequality and happiness: insights from Latin America', The Journal of Economic Inequality, 4: 107-22.

Graham, Carol, Lucas Higuera, and Eduardo A Lora. 2009. 'Valuing health conditionsInsights from happiness surveys across countries and cultures'.

Grootaert, Christian. 1999. 'Social capital, household welfare, and poverty in Indonesia', World bank policy research working paper.

Helliwell, John F. 2006. 'Well- Being, social capital and public policy: What's new?', The Economic Journal, 116: C34-C45.

Helliwell, John F, Haifang Huang, Shawn Grover, and Shun Wang. 2014. 'Good Governance and National Well-being'.

Ipsos. 2011. Tracking Global Happiness (Ipsos: New York).

Jaafar, Jas Laile, Mohd Awang Idris, Jamal Ismuni, Yoo Fei, Salinah Jaafar, Zahir Ahmad, Muhammad Raduan Mohd Ariff, Bagus Takwin, and Yogi Suprayogi Sugandi. 2012. 'The sources of happiness to the Malaysians and Indonesians: data from a smaller nation', Procedia-Social and Behavioral Sciences, 65: 549-56.

Jorgenson, Dale Weldeau. 2002. Econometrics: Economic growth in the information age (MIT Press).

Judge, Timothy A, Daniel Heller, and Michael K Mount. 2002. 'Five-factor model of personality and job satisfaction: a meta-analysis', Journal of applied psychology, 87: 530.

Kessler, Ronald C, Katie A McLaughlin, Jennifer Greif Green, Michael J Gruber, Nancy A Sampson, Alan M Zaslavsky, Sergio Aguilar-Gaxiola, Ali Obaid Alhamzawi, Jordi Alonso, and Matthias Angermeyer. 2010. 'Childhood adversities and adult psychopathology in the WHO World Mental Health Surveys', The British journal of psychiatry, 197: 378-85.

Krueger, Alan B, and David A Schkade. 2008. 'The reliability of subjective well-being measures', Journal of Public Economics, 92: 1833-45.

Lane, Robert Edwards. 2000. The loss of happiness in market democracies (Yale University Press).

Layard, Peter RG, and Richard Layard. 2011. Happiness: Lessons from a new science (Penguin UK).

Lim, Chaeyoon, and Robert D Putnam. 2010. 'Religion, social networks, and life satisfaction', American Sociological Review, 75: 914-33. 
Luo, Ye, and Linda J Waite. 2005. 'The impact of childhood and adult SES on physical, mental, and cognitive well-being in later life', The Journals of Gerontology Series B: Psychological Sciences and Social Sciences, 60: S93-S101.

Miller, Douglas L, Richard Scheffler, Suong Lam, Rhonda Rosenberg, and Agnes Rupp. 2006. 'Social capital and health in Indonesia', World Development, 34: 1084-98.

Oswald, Andrew J, and Stephen Wu. 2011. 'Well-being across America', Review of Economics and Statistics, 93: 1118-34.

Pisani, Elizabeth. 2014. Indonesia, Etc.: Exploring the Improbable Nation (WW Norton \& Company).

Putnam, Robert D, Robert Leonardi, and Raffaella Y Nanetti. 1994. Making democracy work: Civic traditions in modern Italy (Princeton university press).

Rabe-Hesketh, Sophia, and Anders Skrondal. 2008. Multilevel and longitudinal modeling using Stata (STATA press).

Rock, Michael T. 2009. 'Has democracy slowed growth in Asia?', World Development, 37: 941-52.

Rodríguez-Pose, Andrés, and Kristina Maslauskaite. 2012. 'Can policy make us happier? Individual characteristics, socio-economic factors and life satisfaction in Central and Eastern Europe', Cambridge Journal of Regions, Economy and Society, 5: 77-96.

Soldz, Stephen, and George E Vaillant. 1999. 'The Big Five personality traits and the life course: A 45-year longitudinal study', Journal of Research in Personality, 33: 20832.

Stepanikova, Irena, Norman H Nie, and Xiaobin He. 2010. 'Time on the Internet at home, loneliness, and life satisfaction: Evidence from panel time-diary data', Computers in Human Behavior, 26: 329-38.

Stiglitz, J, A. Sen, and J.-P Fitoussi. 2008. "Measurement of economic performance and social progress." In.: Online; accessed 11- January-2013.

Sujarwoto, Sujarwoto, and Gindo Tampubolon. 2013. 'Mother's social capital and child health in Indonesia', Social Science \& Medicine, 91: 1-9.

- 2015. 'Decentralisation and citizen happiness: A multilevel analysis of self-rated happiness in Indonesia', Journal of Happiness Studies, 16: 455-75.

Thomas, Duncan, Firman Witoelar, Elizabeth Frankenberg, Bondan Sikoki, John Strauss, Cecep Sumantri, and Wayan Suriastini. 2012. 'Cutting the costs of attrition: Results from the Indonesia Family Life Survey', Journal of Development Economics, 98: 10823.

Uslaner, Eric M. 1999. 'Democracy and social capital', Democracy and trust: 121-50.

Van Klinken, Gerry. 2007. 'Communal conflict and decentralisation in Indonesia', The Australian Centre for Peace and Conflict Studies Occasional Paper.

Veenhoven, Ruut. 2000. 'Freedom and happiness: A comparative study in forty-four nations in the early 1990s', Culture and subjective well-being: 257-88.

Welsch, Heinz, and Jan Kühling. 2016. 'Macroeconomic performance and institutional change: evidence from subjective well-being data', Journal of Applied Economics, 19: 193-217.

World Bank. 2008. Spending for development: Making the most of Indonesia's new opportunities (World Bank: Washington DC). 2012. World development indicator 2012 (World Bank: Washington DC). 
Average of happiness 2014

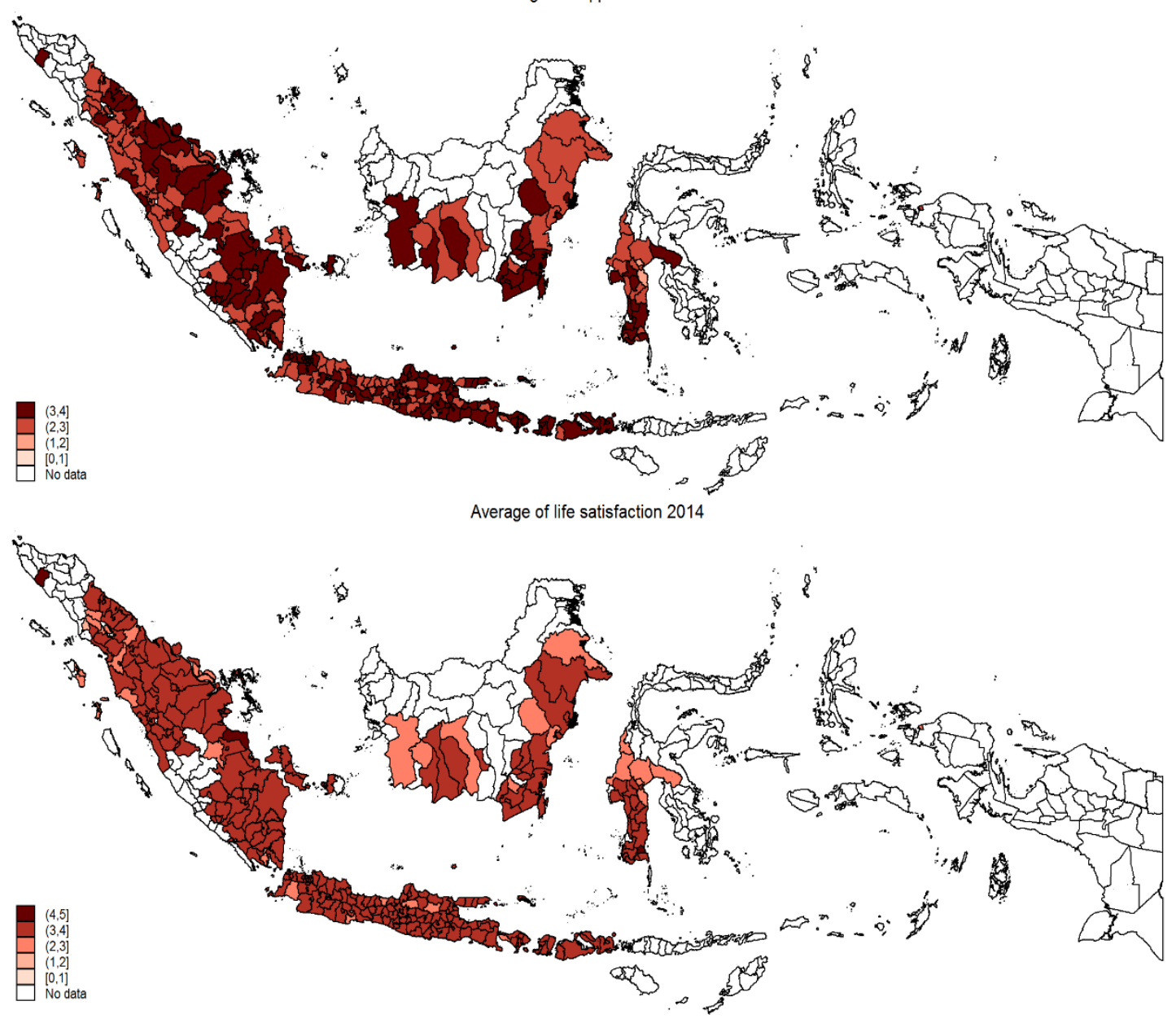

Figure 1. Distribution of happiness and life satisfaction 2014 
Table 1. Summary statistics of sources of happiness and life satisfaction in Indonesia

\begin{tabular}{|c|c|c|c|c|c|c|c|}
\hline Variables & Mean & SD & Min & Max & $\begin{array}{l}\text { Bivariate } \\
\text { correlation } \\
\text { of } \\
\text { happiness }\end{array}$ & $\begin{array}{l}\text { Bivariate } \\
\text { correlation } \\
\text { of life } \\
\text { satisfaction }\end{array}$ & $\begin{array}{l}\% \\
\text { missing }\end{array}$ \\
\hline \multicolumn{8}{|l|}{ Individual level } \\
\hline Happiness & 3.04 & 0.50 & 1 & 4 & 1.00 & $0.34 *$ & 0.00 \\
\hline Life satisfaction & 3.32 & 0.80 & 1 & 5 & $0.34 *$ & $1.00 *$ & 0.00 \\
\hline Age & 38.44 & 18.27 & 14 & 101 & $-0.14 *$ & $-0.09 *$ & 0.02 \\
\hline Female & 0.52 & 0.50 & 0 & 1 & $0.01 *$ & $0.06^{*}$ & 0.02 \\
\hline Married & 0.71 & 0.45 & 0 & 1 & $0.06^{*}$ & $-0.01 *$ & 0.00 \\
\hline Years schooling & 8.65 & 4.47 & 0 & 18 & $0.16^{*}$ & $0.10 *$ & 0.00 \\
\hline Unemployed status & 0.07 & 0.25 & 0 & 1 & $-0.04 *$ & $-0.05^{*}$ & 0.00 \\
\hline Poor health & 0.21 & 0.40 & 1 & 4 & $-0.15^{*}$ & $-0.14 *$ & 0.51 \\
\hline $\begin{array}{l}\text { Poor childhood health } \\
\text { Having emotional, nervous } \\
\text { or psychiatric problem } \\
\text { during child hood }\end{array}$ & $\begin{array}{l}0.37 \\
0.00\end{array}$ & $\begin{array}{l}0.48 \\
0.03\end{array}$ & $\begin{array}{l}0 \\
0\end{array}$ & $\begin{array}{l}1 \\
1\end{array}$ & $\begin{array}{l}-0.06^{*} \\
-0.02^{*}\end{array}$ & $\begin{array}{r}-0.08 * \\
0.00 *\end{array}$ & $\begin{array}{l}0.51 \\
0.51\end{array}$ \\
\hline Religious & 0.76 & 0.42 & 0 & 1 & $0.05 *$ & $0.10^{*}$ & 0.00 \\
\hline $\begin{array}{l}\text { Participate in community } \\
\text { activities }\end{array}$ & 2.04 & 1.76 & 0 & 12 & $0.02 *$ & $0.02 *$ & 0.68 \\
\hline Openness & 3.70 & 0.67 & 1 & 5 & $0.08 *$ & $0.05^{*}$ & 0.57 \\
\hline Conscientiousness & 3.82 & 0.55 & 1 & 5 & $0.08 *$ & $0.06^{*}$ & 0.57 \\
\hline Extroversion & 3.44 & 0.67 & 1 & 5 & $0.08 *$ & $0.06 *$ & 0.57 \\
\hline Agreeableness & 3.90 & 0.51 & 1 & 5 & $0.05^{*}$ & $0.05^{*}$ & 0.57 \\
\hline Neuroticism & 2.68 & 0.67 & 1 & 5 & $-0.07 *$ & $-0.06 *$ & 0.57 \\
\hline Loneliness & 0.05 & 0.23 & 0 & 1 & $-0.03 *$ & $-0.01 *$ & 0.02 \\
\hline $\begin{array}{l}\text { Using mobile phone for } \\
\text { entertainment }\end{array}$ & 0.42 & 0.49 & 0 & 1 & $0.12 *$ & $0.09 *$ & 0.00 \\
\hline \multicolumn{8}{|l|}{$\begin{array}{l}\text { Household level } \\
\text { Log household }\end{array}$} \\
\hline \multicolumn{8}{|l|}{ District level } \\
\hline $\begin{array}{l}\text { Log GDP } \\
\text { Log spending on public }\end{array}$ & 10.15 & 1.22 & 6.62 & 12.97 & $0.02 *$ & $0.03 *$ & 0.00 \\
\hline services & 12.59 & 0.54 & 10.71 & 14.46 & $0.02 *$ & $0.03 *$ & 6.85 \\
\hline Conflicts and violence & 12.86 & 16.87 & 0 & 78 & $-0.01 *$ & $-0.01 *$ & 0.00 \\
\hline Democracy index & 73.04 & 5.73 & 62.62 & 84.70 & -0.01 & -0.01 & 0.00 \\
\hline Community social capital & 0.95 & 0.06 & 0.59 & 1 & $0.03 *$ & $0.04 *$ & 0.00 \\
\hline
\end{tabular}

Percent missing is calculated from the total number of individual-level observation $(\mathrm{N}=31,403)$. Reported associations are the coefficient of simple bivariate logit regression analysis, ${ }^{*} \mathrm{p}<.05$ 
Table 2. Results of three level ordered logistic regression of happiness and life satisfaction

\begin{tabular}{|c|c|c|c|c|c|c|c|c|}
\hline & \multicolumn{4}{|c|}{ Three level ordered logistic regression } & \multicolumn{4}{|c|}{ Marginal effects } \\
\hline & \multicolumn{2}{|c|}{ Happiness } & \multicolumn{2}{|c|}{ Life satisfaction } & \multicolumn{2}{|c|}{ Happiness } & \multicolumn{2}{|c|}{ Life satisfaction } \\
\hline & Coef. & SE & Coef. & $\mathrm{SE}$ & Coef. & SE & Coef. & $\mathrm{SE}$ \\
\hline Age & $-0.27 *$ & 0.04 & $-0.20 *$ & 0.03 & $-0.04 *$ & 0.00 & $-0.03 *$ & 0.00 \\
\hline $\mathrm{Age}^{2}$ & $0.02 *$ & 0.00 & $0.01 *$ & 0.00 & $0.01 *$ & 0.00 & $0.01 *$ & 0.00 \\
\hline Female & 0.01 & 0.01 & $0.12 *$ & 0.01 & 0.01 & 0.01 & $0.12 *$ & 0.01 \\
\hline Married & $0.09 *$ & 0.01 & $0.05^{*}$ & 0.02 & $0.09 *$ & 0.01 & $0.05^{*}$ & 0.01 \\
\hline Years schooling & $0.01 *$ & 0.00 & $0.00 *$ & 0.00 & $0.01 *$ & 0.00 & $0.01 *$ & 0.00 \\
\hline Unemployed status & $-0.08^{*}$ & 0.01 & $-0.12 *$ & 0.02 & $-0.08 *$ & 0.01 & $-0.12 *$ & 0.02 \\
\hline Poor health & $-0.06^{*}$ & 0.00 & $-0.11 *$ & 0.01 & $-0.06^{*}$ & 0.00 & $-0.11^{*}$ & 0.01 \\
\hline Poor childhood health & $-0.04 *$ & 0.01 & $-0.08 *$ & 0.01 & $-0.04 *$ & 0.01 & $-0.08^{*}$ & 0.01 \\
\hline $\begin{array}{l}\text { Having emotional, nervous or } \\
\text { psychiatric problem during child } \\
\text { hood }\end{array}$ & $-0.32 *$ & 0.13 & -0.04 & 0.21 & $-0.32 *$ & 0.03 & $-0.04 *$ & 0.01 \\
\hline Religious & $0.05 *$ & 0.01 & $0.19^{*}$ & 0.01 & $0.05^{*}$ & 0.01 & $0.19 *$ & 0.01 \\
\hline Participate in community activities & $0.05^{*}$ & 0.00 & $0.04^{*}$ & 0.00 & $0.03 *$ & 0.00 & $0.02 *$ & 0.00 \\
\hline Openness & 0.01 & 0.01 & 0.01 & 0.01 & 0.01 & 0.01 & -0.01 & 0.01 \\
\hline Conscientiousness & $0.04 *$ & 0.01 & $0.05^{*}$ & 0.01 & $0.04 *$ & 0.01 & $0.05^{*}$ & 0.01 \\
\hline Extroversion & $0.03 *$ & 0.00 & $0.03^{*}$ & 0.01 & $0.03 *$ & 0.00 & $0.02 *$ & 0.01 \\
\hline Agreeableness & $0.03 *$ & 0.01 & $0.04 *$ & 0.01 & $0.03 *$ & 0.01 & $0.04^{*}$ & 0.01 \\
\hline Neuroticism & $-0.03 *$ & 0.01 & $-0.04 *$ & 0.01 & $-0.03 *$ & 0.01 & $-0.04 *$ & 0.01 \\
\hline Loneliness & $-0.09 *$ & 0.01 & $-0.08 *$ & 0.02 & $-0.09 *$ & 0.01 & $-0.08^{*}$ & 0.02 \\
\hline $\begin{array}{l}\text { Using mobile phone for } \\
\text { entertainment } \\
\text { Household level }\end{array}$ & $0.06 *$ & 0.01 & $0.06^{*}$ & 0.01 & $0.03 *$ & 0.01 & $0.06^{*}$ & 0.01 \\
\hline $\begin{array}{l}\text { Log household expenditure } \\
\text { District level }\end{array}$ & $0.03 *$ & 0.00 & $0.06^{*}$ & 0.00 & $0.03 *$ & 0.00 & $0.06^{*}$ & 0.00 \\
\hline Log GDP & $0.11 *$ & 0.01 & $0.12 *$ & 0.01 & $0.01^{*}$ & 0.01 & $0.02 *$ & 0.01 \\
\hline Log spending on public services & $0.12 *$ & 0.01 & $0.11^{*}$ & 0.02 & $0.02 *$ & 0.01 & $0.01 *$ & 0.02 \\
\hline Conflicts and violence & $-0.09 *$ & 0.00 & $-0.10^{*}$ & 0.00 & $-0.07^{*}$ & 0.00 & $-0.08^{*}$ & 0.00 \\
\hline Democracy index & 0.00 & 0.00 & 0.00 & 0.00 & 0.00 & 0.00 & 0.00 & 0.00 \\
\hline Community social capital & $0.23 *$ & 0.06 & $0.69 *$ & 0.09 & $0.13^{*}$ & 0.06 & $0.31 *$ & 0.09 \\
\hline$K_{l}$ & $0.63^{*}$ & -0.05 & $0.84^{*}$ & -0.16 & & & & \\
\hline$K_{2}$ & $2.89^{*}$ & 1.00 & $3.12 *$ & 1.12 & & & & \\
\hline$K_{3}$ & $7.59^{*}$ & 2.30 & $5.30^{*}$ & 2.30 & & & & \\
\hline$K_{4}$ & & & $8.28^{*}$ & 3.28 & & & & \\
\hline$\sigma_{e \text { District }}^{2}$ & 0.06 & $0.01 *$ & 0.07 & $0.01 *$ & & & & \\
\hline$\sigma_{e \text { Household }}^{2}$ & 0.43 & $0.02 *$ & 0.41 & $0.03 *$ & & & & \\
\hline ICC & 0.18 & & 0.20 & & & & & \\
\hline $\mathrm{N}$ & 31,403 & & 31,403 & & & & & \\
\hline
\end{tabular}

Note: reported marginal effect at means, ${ }^{*} \mathrm{p}<5 \%$ 